\title{
ESTIMATING CARBON SEQUESTRATION RATES AND TOTAL CARBON STOCKPILE IN DEGRADED AND NON-DEGRADED SITES OF OAK AND PINE FOREST OF KUMAUN CENTRAL HIMALAYA
}

\author{
B.S. Jina, Pankaj Sah, M.D. Bhatt** and Y.S. Rawat* \\ Department of Botany \\ Kumaun University, Nainital, Uttarakhand, India \\ * Department of Biotechnology \\ Government P.G. College, Haldwani, Nainital, Uttarakhand, India \\ **Department of Botany \\ Siddhanath Science Campus, Mahendranagar (T. U.), Nepal \\ **Email: bhattmd@rediffmail.com
}

\begin{abstract}
We calculated the rates at which $\mathrm{CO}_{2}$ is being sequestered in two different forest types of Himalaya. For our comparative study we took the degraded and non-degraded sites of pine and oak forests in Kumaun Central Himalaya. The Van Panchayats (VPs) or Community Forests are managing the nondegraded forest sites for centuries, and from this research we have come to know that the sequestration of $\mathrm{CO}_{2}$ in these non-degraded forests is significantly greater than the degraded forests. The paper recommends the significance of community forests in both Uttarakhand and the world, and advocates that if we want to fight against global warming, we must encourage the community forests and that the people living in severe poverty in these forest areas who become the unsung heroes in the war against global warming, must be paid in lieu of saving their forests, which ultimately become the sink for increased $\mathrm{CO}_{2}$ worldwide. This business or 'carbon trading' will indeed evolve as the panacea against the war against global warming.
\end{abstract}

Key words: Carbon sequestration, community forests, Van Panchayats, green house gases, global warming, carbon trading.

\section{INTRODUCTION}

Carbon, in the form of carbon dioxide $\mathrm{CO}_{2}$ is accumulating in the atmosphere at a rate of about 3.5 billion metric tones per annum as a result of fossil fuel combustion, tropical deforestation and forest fuel combustion. The accumulation of carbon dioxide $\left(\mathrm{CO}_{2}\right)$ and other greenhouse gases
(GHGs) in the atmosphere is expected to cause observable climatic changes in the coming century. The Kyoto Protocol to the United Nations Framework Convention on Climatic Change, if ratified, will require developed nations to reduce their net carbon emission in the period 2008-2012 to less than what was emitted in 1990. 
Approximately $22 \%$ of the annual global carbon dioxide emission results from human activities such as deforestation. There are various gases in the earth's lower atmosphere i.e. troposphere that cause the greenhouse effect (GHE) such as carbon dioxide $\left(\mathrm{CO}_{2}\right)$, chlorofluoro carbons (CFC's), Ozone $\left(\mathrm{O}_{3}\right)$, methane $\left(\mathrm{CH}_{4}\right)$, water vapour and nitrous oxide $\left(\mathrm{NO}_{2}\right)$.

If the atmospheric concentrations of these green house gases rise and other natural processes do not remove them, the average temperature of the lower atmosphere will progressively amplify which could be hazardous for living organisms in the long run. In other words, there are number of factors which can change or affect the balance between the energy absorbed and emitted, such as

i. Changes in the sun's energy out put,

ii. Slow variations in the earth's orbit,

iii. The green house effect raising the global temperature may trigger a series of changes within the overall global climate system.

Carbon sequestration can be defined as the removal of $\mathrm{CO}_{2}$ from atmosphere (source) into green plants (sink) where it can be stored indefinitely (Watson et al. 2000). These sinks can be above ground biomass (trees) or living biomass below the ground in soil (roots and micro organisms) or in the deeper sub-surface environments. Sequestration, which is relatively a new term, can be described as storage of all forms of carbon, including storage in terrestrial, geological and oceanic ecosystem. Through practices and technologies sequestration seeks to quantify and enhance the storage ability of all potential sinks and expand the number and type of sinks in which carbon storage is possible. Enhancing the natural processes that remove $\mathrm{CO}_{2}$ from the atmosphere is thought to be one of the most useful methods of mitigating the atmospheric levels of $\mathrm{CO}_{2}$.
There are three basic approaches to sequester carbon in terrestrial ecosystems, which are as follows-

i. Increasing the inputs of carbon (GPP and NPP) to an ecosystem,

ii. Partitioning carbon to longer lived pools, and

iii. Increasing the consistency of (possible existing) carbon pools. The general goal of sequestration activities is to maintain ecosystem in the sink phase. However, if the system is disturbed (a forest burns or is harvested or land is cultivated), a large fraction of previously accumulated carbon may be released into the atmosphere through combustion or decomposition.

The carbon sequestration program has performed an analysis of the role that carbon capture and storage can play in helping the world to stabilize and consequently diminish the greenhouse gas emission. It leads to the storage and capture of $\mathrm{CO}_{2}$ and other GHGs that would otherwise be emitted into the atmosphere. The greenhouse gases can be captured at the emission source, or can be removed from the air. The captured gases can be stored in underground reservoirs, dissolved in deep oceans, converted to rock like solid material, or absorbed by trees, grasses, soils and algae. Due to industrialization and reduction of carbon pools in past few decades the concentrations of $\mathrm{CO}_{2}$ in the atmosphere has rapidly increased.

The problem of anthropogenic carbon dioxide accumulation in the atmosphere can be addressed either by reducing $\mathrm{CO}_{2}$ emission or by developing carbon sinks. The Kyoto Protocol of the UN framework convention on climate change (UNFCCC) was the first step taken by the international community in this direction. For developing carbon sinks, much of the emphasis was given at Kyoto pertained to afforestation and 
reforestation programmes. While the conservation of existing forests was generally neglected, one of the major features in Kyoto conference was to set caps on each country's $\mathrm{CO}_{2}$ emission. In 2001, it was agreed that reforestation activities eligible for carbon trading would be restricted to plantation on lands that did not contain forest prior to 1990 . Now it is being increasingly realized that prevention of deforestation should be considered within the framework of the Kyoto Protocol implementation and it is important to conserve local communities, which are dependent on biomass for their living. It is being argued that community forest management may play a significant role in carbon saving.

Threats to biodiversity are great and nearly half of the forest area in Uttarakhand is in a degraded state, and the region has become a net source of carbon release to the atmosphere. In the western Himalaya, the state of Uttarakhand occupies a special place; in participatory management of common resources because of its Van Panchayats, which easily represent one of the largest and oldest institutions based on collaboration between the state and community.

The present study is an attempt to estimate the carbon sequestration rates and stock in two major forest types, Chir-Pine and Banj-Oak that occupy $16.36 \%$ and $12.29 \%$ of land area, respectively in Uttarakhand under varying levels of disturbances (Uttarakhand Forest Statistics 2004-2005, Forest Department, Uttarakhand) in three Van Panchayat forests in Lamgara block of Almora, Uttarakhand.

\section{MATERIALS AND METHODS}

The selected sites are located in the Van Panchayats (VPs) of Dhaili, Toli, and Guna positioned in Lamgara block of Almora district in Uttarakhand. The Van Panchayats of Dhaili, Toli, and Guna are situated between $79^{\circ} 41.44^{\prime}-79^{\circ} 43.2^{\prime}$ E longitudes and $29^{\circ} 32.98^{\prime}-29^{\circ} 34.32^{\prime}$ latitudes. The elevation of these Van Panchayats varies from
$1800-2000 \mathrm{~m}$. Altitudinally the study area is located in a temperate environment but latitudinally it comes within the subtropical belt. The basic climate pattern is governed by the monsoon rhythm. The monsoon strikes this area from mid-June to the mid-September, which sometimes extends up to late September and first week of October. The maximum rainfall occurs during July and August. The total rainfall recorded in the year 2004 was $832.0 \mathrm{~mm}$ and in 2005 was $921.9 \mathrm{~mm}$ in Lamgara block. The mean maximum temperature varied from $16.7^{\circ} \mathrm{C}$ (January) to $31.5^{\circ} \mathrm{C}$ (June) and the mean minimum from $6.5^{\circ} \mathrm{C}$ (January) to $19.2^{\circ} \mathrm{C}$ (June) in 2004. In 2005 the mean maximum temperature varied from $17.0^{\circ} \mathrm{C}$ (January) to $32.6^{\circ} \mathrm{C}$ (June) and the mean minimum from $5.8^{\circ} \mathrm{C}$ (January) to $19.5^{\circ} \mathrm{C}$ (June) in 2004 .

Originally referred to as the crystalline zone of Almora by Heim and Gansser (1939) and commonly known "Almora crystalline", this vast over thrust succession of a variety of schist's, micaceous quartizimeta morphism and with concordantly emplaced plutonic bodies of granodiorites and granites is renamed Almora group (Valdiya 1980) after the township of Almora.

\section{Selection criteria for degraded and non- degraded forests}

Presence or absence of regeneration: The presence or absence of regeneration in degraded and non-degraded oak (Quercus leucotrichophora) and pine (Pinus roxburghii) forests was the most important criteria for selection of degraded and non-degraded forest sites.

Crown cover: The sites with less than $40 \%$ crown cover were considered as degraded and those having crown cover above $60 \%$ as non-degraded.

Number of lopped branches/tree: In degraded and non-degraded Pine and Oak forests, the numbers of lopped branches per tree (taking 10 
trees) were measured by counting branches per tree. The sites where the lopped branches were $50 \%$ and more were considered as degraded and sites having less than $20 \%$ lopped branches/tree as non-degraded.

Fodder extraction: Another norm for selection of degraded and non-degraded sites was head loads of fodder extracted. Sites from where fodder extracting was only for a few weeks in a year, were taken as non-degraded and sites having no restriction on fodder extraction as degraded.

Grazing: In non-degraded sites the animal grazing was totally banned, but the degraded sites were open for grazing throughout the year.

The boundaries of different forest types were identified and marked on a map of the area. The permanent plots were systematically laid down with a random starting point marked each stratum. Transects perpendicular to the longest side of the stratum were placed for a reasonable spread of the plots over the whole area. Transects were placed parallel to each other, and the length of transects and their bearings were recorded using a compass. The plots were marked at a similar distance from each other and the maps of their locations were prepared. The center of the plot was marked by a tree with white circle and the radius of the circular plot was taken from the center of this tree. All the individuals $>16 \mathrm{~cm}$ circumference at breast height were measured as trees over the entire plot of 5.64 $\mathrm{m}$ radius, saplings were $<16 \mathrm{~cm}$ but $>4 \mathrm{~cm}$ and seedling were $<4 \mathrm{~cm}$ (Skutsch and Zahabu 2003). Based on the field data the following girth classes of trees were recognized: $16-25 \mathrm{~cm}, 26-50 \mathrm{~cm}, 51-$ $75 \mathrm{~cm}, 76-100 \mathrm{~cm}, 101-125,126-150 \mathrm{~cm}$ and $>150$ cm (Rawat and Singh 1988).

\section{Estimation of Carbon Stock and Carbon Sequestration Rates}

For the estimation of Carbon stock and carbon sequestration rates in the studied forest types, we measured tree biomass and net primary productivity. For this study the circumference of marked trees in each permanent plot was taken at $1.37 \mathrm{~m}$ from the ground level in December 2004. Using the allometric equations developed by Chaturvedi and Singh (1987) and Rawat and Singh (1988) the biomass of different components (bole, branch, twig foliage, stump root, lateral root and fine roots) of trees was calculated from the cbh measurement. Measurements of circumference were taken on the same marked trees in permanent plots again in Dec 2005 and biomass estimation was done. Change in biomass $\left(\Delta \mathrm{B}=\mathrm{B}_{2}-\mathrm{B}_{1}\right)$ was taken as annual biomass accumulation. The sum of $\Delta \mathrm{B}$ values for different components were taken for accretion of biomass in trees.

For the estimation of sapling and seedling biomass, 10 quadrats of $5 \mathrm{~m} \times 5 \mathrm{~m}$ and $0.5 \mathrm{~m} \times 0.5$ $\mathrm{m}$ were randomly placed, respectively on each site. Biomass was estimated on the basis of allometric equations developed by Chaturvedi and Singh (1987) and Rawat and Singh (1988). For the estimation of total shrubs, herbs and litter biomass the quadrats of $5 \mathrm{~m} \times 5 \mathrm{~m}, 1 \mathrm{~m} \times 1 \mathrm{~m}$ and $50 \mathrm{mx}$ $50 \mathrm{~cm}$, respectively, were placed randomly on each site. The biomass of herbs at all sites was determined during rainy season (the peak growth period). The herbs and shrubs in each quadrat were harvested and the litter from each quadrate were placed in paper bags and brought to the laboratory. The samples were oven dried at $80^{\circ} \mathrm{C}$ to constant weight. The net primary production for tree, shrub, herb and litter layers was calculated in each site according to Rana et al. (1989).

Carbon stock and carbon sequestration rates were estimated as $50 \%$ of the dry weight of biomass and $50 \%$ of net primary productivity, respectively (Hamberg 2000, Brown 2001).

\section{RESULTS AND DISCUSSION}

In most of the ecosystems, carbon is stored in the plant biomass in Sal and Oak dominated 
forests, the proportion being 80-92\%, while in Chir Pine and Chir Pine dominated forests, biomass accounts for just a little more than $50 \%$ of the ecosystem carbon. All the Central Himalayan forests ecosystem studied are aggrading in nature and show net carbon accumulation, generally 6-7 t $\mathrm{ha}^{-1} \mathrm{yr}^{-1}$ (Singh and Singh 1985). The assumption that $50 \%$ of biomass (as a dry weight basis) is carbon is well accepted (Hamburg 2000, Brown 2001).

In non-degraded Oak site of the present investigation, the carbon stock in forest biomass ranged from 242.56-290.62 $\mathrm{t} \mathrm{ha}^{-1}$, while in degraded site the stock ranged between 16.73$18.54 \mathrm{t} \mathrm{ha}^{-1}$ (Table 1). In non-degraded Chir Pine site, the carbon stock varied from 81.31-115.40 t $\mathrm{ha}^{-1}$, while in degraded Pine site ranged between 17.59-33.42 $\mathrm{t} \mathrm{ha}^{-1}$ (Table 1). The present findings of oak forests are in conformity with the findings of Rana et al. (1989). Malhi et al. (1998) states that in the Indian Himalayan Forests, average carbon stock is $148 \mathrm{t} \mathrm{ha}^{-1}$. When we average the carbon, across all the forests studied (degraded and non-degraded), our values are even lower in Banj Oak and Chir Pine (142 t ha ${ }^{-1}$ and $62 \mathrm{t} \mathrm{ha}^{-1}$, respectively).

The carbon sequestration rates in degraded and non-degraded sites of Banj Oak ranged from 1.47 to $6.23 \mathrm{t} \mathrm{ha}^{-1} \mathrm{yr}^{-1}$, while in Chir Pine 1.07 to $6.66 \mathrm{t}$ $\mathrm{ha}^{-1} \mathrm{yr}^{-1}$. The mean carbon sequestration rates were higher in non-degraded sites of oak and pine forests $\left(5.86 \mathrm{t} \mathrm{ha}^{-1} \mathrm{yr}^{-1}\right)$ as compared to degraded sites of oak and pine forest (1.41 $\left.\mathrm{tha}^{-1} \mathrm{yr}^{-1}\right)$. The carbon sequestration rate was higher by $70.05 \%$ $73.06 \%$ in non-degraded site of Oak compared to degraded Oak site; similarly in Pine non-degraded site the sequestration rate was more by $74.92 \%$ $83.9 \%$ in comparison to Pine degraded sites. The carbon sequestration rates in degraded sites were significantly $(\mathrm{P}<0.001)$ lower than non-degraded sites in both the forest types (Table 1).

Table 1. Variations in carbon sequestration rates of degraded and non-degraded sites of Banj Oak and Chir Pine forest in different Van Panchayats (VPs).

\begin{tabular}{|c|c|c|c|}
\hline Name of VP's & $\begin{array}{c}\text { Carbon stock in } 1^{\text {st }} \\
\text { year }\left(B_{1}\right) \\
\left(\mathrm{t} \mathrm{ha}^{-1}\right)\end{array}$ & $\begin{array}{c}\text { Carbon stock in } 2^{\text {nd }} \\
\text { year }\left(B_{2}\right) \\
\left(\mathrm{t} \mathrm{ha}^{-1}\right)\end{array}$ & $\begin{array}{c}\text { Carbon sequestration } \\
\text { rate } \Delta B=B_{2}-B_{1} \\
\left(t h^{-1} \mathbf{y r}^{-1}\right)\end{array}$ \\
\hline \multicolumn{4}{|l|}{ Oak non-degraded site } \\
\hline Guna Van Panchayat & 290.62 & 296.09 & 5.48 \\
\hline Dhaili Van Panchayat & 242.56 & 248.79 & 6.23 \\
\hline \multicolumn{4}{|l|}{ Pine non-degraded site } \\
\hline Toli Van Panchayat & 81.31 & 86.37 & 5.06 \\
\hline Guna Van Panchayat & 115.40 & 122.06 & 6.66 \\
\hline \multicolumn{4}{|l|}{ Oak degraded site } \\
\hline Dhaili Van Panchayat & 18.54 & 20.38 & 1.84 \\
\hline Guna Van Panchayat & 16.73 & 18.20 & 1.47 \\
\hline \multicolumn{4}{|l|}{ Pine Degraded site } \\
\hline Guna Van Panchayat & 17.59 & 18.66 & 1.07 \\
\hline Toli Van Panchayat & 33.42 & 34.69 & 1.27 \\
\hline
\end{tabular}

$\mathrm{B}_{1}=1^{\text {st }}$ year carbon stock, $\mathrm{B}_{2}=2^{\text {nd }}$ year carbon stock, $\Delta \mathrm{B}=$ change in carbon sequestration rate 
Table 2. Comparison of carbon stock and carbon sequestration rates across various forest types in the world with the current values.

\begin{tabular}{|c|c|c|c|}
\hline Forest type & $\begin{array}{c}\text { Carbon stock } \\
\left(\mathrm{t} \mathrm{ha}^{-1}\right)\end{array}$ & $\begin{array}{c}\text { Annual increment in } \\
\text { carbon stock of } \\
\text { biomass }\left(\mathrm{t} \mathrm{ha}^{-1} \mathrm{yr}^{-1}\right)\end{array}$ & References \\
\hline Tropical forest of the world & 285.0 & 2.30 & \\
\hline Temperate forest of the world & 125.0 & 4.19 & Malhi (1998), Press et al(2000) \\
\hline Boreal forest of the world & 67.0 & 1.40 & \\
\hline $\begin{array}{l}\text { Pre-dominant range of the forest } \\
\text { type of the world }\end{array}$ & $50-150$ & - & Lal (2004) \\
\hline All central Himalayan forests & $250-300$ & $6.0-8.0$ & Singh and Singh $(1985,1992)$ \\
\hline Seven central Himalayan forests & $166.8-440.10$ & $6.83-7.42$ & Rana et al. (1989) \\
\hline $\begin{array}{l}\text { Chir pine and banj oak non- } \\
\text { degraded forests }\end{array}$ & $173.7-262.6$ & $5.06-6.66$ & Present study \\
\hline $\begin{array}{l}\text { Chir pine and banj oak degraded } \\
\text { forest }\end{array}$ & & $1.07-1.84$ & \\
\hline
\end{tabular}

Rana et al. (1989), Malhi et al. (1998) and Press et al. (2000) have reported similar ranges for carbon sequestration rates of banj oak and chir pine forests (Table 2).

\section{CONCLUSIONS}

The studied VPs forests sequester carbon at the rate of 4-5 $\mathrm{t} \mathrm{ha}^{-1} \mathrm{yr}^{-1}$. As the mean area of a VP is $60 \mathrm{ha}$, it sequesters a total of $240 \mathrm{t}$ carbon $\mathrm{ha}^{-1}$ $\mathrm{yr}^{-1}$ worth US \$3120 annually at the rate of US\$ 13 per ton. Once the people start realizing that the carbon of their forests is saleable they will be motivated to conserve them.

\section{ACKNOWLEDGEMENT}

Authors are thankful to the Head, Department of Botany, DSB Campus, Kumaun University Nainital for providing necessary facilities and encouragement throughout the study period. Mr. Mukund Kumaiyan also deserves special mention for statistical analysis.

\section{REFERENCES}

Brown, S. 2001. Measuring and monitoring carbon benefits for forest-based projects: experience from pilot projects, can carbon sinks be operational? Resources for the Future (RFF) workshop proceedings. Washington DC, pp. 119.

Chaturvedi, O.P. and J.S. Singh. 1987. The structure and function of pine forest in Central Himalaya. I. Dry matter dynamics. Annals of Botany 60:237-252.

Hamburg, S.P. 2000. Simple rules for measuring changes in ecosystem carbon in forestryoffset projects. Mitigation and Adaptation Strategies for Global Change, 5:25-37.

Heim and Gansser. 1939. Central Himalaya geological observation of the swiss expedition. Mem. Soc. Helv. Sci. Nat. 73:1-245.

Lal, R. 2004. Soil carbon sequestration impacts on global climate change and food security. Science 304: 1623-1626.

Malhi, Y., A.D. Nobre and J. Grace. 1998. Carbon dioxide transfer over a central Amazonian rain forest. Journal of Geophysical Research 103:593-631.

Press, M.C., N.J. Huntley and S. Levin. 2000. Ecology: Achievements and Challenge. Blackwell Science, Oxford, UK. 
Rana, B.S., S.P. Singh and R.P. Singh. 1989. Carbon and energy dynamic of seven Central Himalayan forests. Tropical Ecology 30(2):253-264.

Rathore, S.K.S., S.P. Singh, J.S. Singh and A.K. Tewari. 1997. Changes in forest cover in central Himalayan catchment: Inadequacy of assessment based on forest areas alone. Journal of Environment Management 49:265276.

Rawat, Y.S. and J.S. Singh. 1988. Structure and function of oak forests in central Himalaya. I. dry matter dynamics. Annals of Botany 62:397-411.

Singh, J.S. and S.P. Singh. 1992. Forests of Himalaya- Structure, Functioning and Input of Man. Gyanodaya Prakashan, Nainital, India.

Singh, S.P. and J.S. Singh. 1985. Man and Environment: The Central Himalayan Case. Biol. Mem. 11(1):47-59.
Singh, S.P. and J.S. Singh. 1985. Survey of patterns and processes in ecosystems of the Himalayan ranges. Trends in Plant Research pp. 473-485.

Skutsch, M.M. and Zahabu. 2003. Revised field protocol for measuring carbon sequestered in forest. Twenty University, Netherlands.

Valdiya, K.S. 1980. Geology of Kumaun Lesser Himalaya. Wadia institute of Himalayan Geology, Dehradun, 291 p.

Watson, R.T., I.R. Noble, B. Bolin, N.H. Ravindranathan and D.J. Verardo (eds.). 2000. Land Use, Land Use Change and Forestry. Special report of the intergovernmental panel on climate change. Cambridge University Press, Cambridge, UK. 